\title{
EFEITO DA ASSOCIAÇÃO DO FATOR DE CRESCIMENTO EPIDERMAL COM CISTEAMINA DURANTE A MATURAÇÃO IN VITRO DE OÓCITOS BOVINOS
}

\section{EFECTO DE LA ASOCIACIÓN DEL FACTOR DE CRECIMIENTO EPIDÉRMICO CON CISTEAMINA DURANTE LA MADURACIÓN IN VITRO DE OVÓCITOS BOVINOS}

\section{EFFECT OF EPIDERMAL GROWTH FACTOR ASSOCIATION WITH CYSTEAMINE DURING IN VITRO MATURATION OF BOVINE OOCYTES}

Antonia Rafaela da Silva Oliveira ${ }^{1}$; Maria Valéria de Oliveira Santos ${ }^{2}$; Lhara Ricarliany Medeiros de Oliveira ${ }^{3}$; Alexsandra Fernandes Pereira ${ }^{4}$

DOI: $\underline{\text { https://doi.org/10.31692/978-65-991061-4-9.145-150 }}$

\section{INTRODUÇÃO}

As biotécnicas reprodutivas como a produção in vitro de embriões (PIVE) têm sido amplamente empregadas para melhorar a produtividade de bovinos de grande interesse econômico. Contudo, a eficiência da PIVE ainda é variável e alguns ajustes podem ser realizados nas suas etapas para alcançar melhores resultados. Assim, na etapa de maturação in vitro, a suplementação do meio com substâncias capazes de promover a maturação e garantir a competência oocitária, como a cisteamina (CIS) e o fator de crescimento epidermal (EGF), tem sido uma estratégia interessante (OYAMADA et al., 2004; SOVERNIGO et al., 2017). Assim, o objetivo foi avaliar o efeito de CIS e do EGF em combinação durante a maturação de oócitos bovinos. Para tanto, oócitos foram maturados por $24 \mathrm{~h}$ em meio contendo CIS, EGF e a combinação de CIS e EGF. Após esse período, oócitos foram avaliados quanto à expansão e viabilidade das células do cumulus, maturação nuclear oocitária e níveis de espécies reativas de oxigênio em oócitos maturados. Finalmente, os resultados obtidos mostraram que a combinação CIS e EGF não influencia na maturação nuclear de oócitos bovinos; contudo, a cisteamina é importante para a viabilidade das células do cumulus.

\section{FUNDAMENTAÇÃO TEÓRICA}

A bovinocultura para produção de carne e leite tem passado por um constante processo de modernização diretamente relacionado aos avanços tecnológicos associados às biotécnicas

\footnotetext{
${ }^{1}$ Bolsista do Programa de Educação Tutorial (PET) - Zootecnia, Universidade Federal Rural do Semi-Árido (UFERSA), rafacosta2@live.com

${ }^{2}$ Doutoranda em Ciência Animal, UFERSA, valeriasnts07@gmail.com

${ }^{3}$ Mestranda em Ciência Animal, UFERSA, lharagirs@ hotmail.com

${ }^{4}$ Doutora em Ciências Veterinárias, Prof. UFERSA, alexsandra.pereira@ufersa.edu.br
} 
reprodutivas (SINGH et al., 2019). Nesse contexto, a produção in vitro de embriões (PIVE) tem sido amplamente empregada, permitindo a obtenção de um maior número de crias por fêmea, seleção de doadores de gametas de alto valor genético, aproveitamento genético de indivíduos jovens e senis e de animais com dificuldade reprodutiva adquirida por questões filogenéticas (RUMPF, 2007).

A PIVE pode ser dividida em algumas etapas principais, iniciando com a maturação in vitro (MIV) de oócitos, fecundação in vitro (FIV) e desenvolvimento embrionário in vitro (DIV). Assim, sendo a MIV a primeira etapa de cultivo e o momento no qual os oócitos adquirem competência para o desenvolvimento embrionário posterior, faz-se necessário aperfeiçoar as condições de cultivo para aumentar a taxa de maturação e a qualidade do oócito maturado.

Estudos mostraram que oócitos maturados in vivo são mais competentes que oócitos maturados in vitro e, provavelmente, isso está relacionado à maturação citoplasmática e expressão gênica (DIELEMAN et al., 2002; SIRARD et al., 2007). Nesse contexto, algumas suplementações têm sido associadas a melhorias na competência oocitária, como o fator de crescimento epidermal (EGF) e a cisteamina (CIS). O EGF promove a retomada meiótica do oócito e a expansão da matriz das células cumulus, melhorando a competência de desenvolvimento embrionário (WATSON et al., 2000; OYAMADA et al., 2004). Já a cisteamina atua como antioxidante e estimula a produção de glutationa que está relacionada à competência do oócito (SOVERNIGO et al., 2017). Assim, acredita-se que a associação desses dois suplementos no meio de MIV poderia melhorar a taxa de maturação e qualidade do oócito bovino. Portanto, o objetivo foi avaliar o efeito da associação de EGF e CIS durante a MIV sobre a expansão e viabilidade das células do cumulus, bem como a maturação nuclear oocitária e níveis de espécies reativas de oxigênio em oócitos.

\section{METODOLOGIA}

Os ovários foram recuperados de fêmeas bovinas oriundas de um abatedouro local e transportados ao laboratório em solução salina aquecida $\left(35-37^{\circ} \mathrm{C} ; \mathrm{NaCl} 0,9 \%\right)$. No laboratório, os folículos com diâmetro de 2-8 mm foram aspirados usando agulha de $21 \mathrm{G} \mathrm{e}$ seringa de $5 \mathrm{~mL}$ contendo meio de colheita e manipulação (MCM: TCM199 suplementado com 2,2 g/L de bicarbonato sódio, $25 \mathrm{mM}$ de HEPES, 10\% de SFB, 0,2 $\mathrm{mM}$ de piruvato de sódio e $1 \%$ de solução de antibióticos e antimicóticos).

Em seguida, os oócitos recuperados foram classificados e somente aqueles com mais de uma camada de células do cumulus e citoplasma homogêneo foram utilizados para a MIV. 
Portanto, para este estudo experimental de natureza quantitativa, oócitos imaturos viáveis foram divididos em três grupos experimentais: (i) $100 \mu \mathrm{M}$ de cisteamina, (ii) $10 \mathrm{ng} / \mathrm{mL}$ de EGF; e (iii) $100 \mu \mathrm{M}$ de cisteamina combinado com $10 \mathrm{ng} / \mathrm{mL}$ de EGF. Para a MIV, os oócitos foram incubados em MCM suplementado com $20 \mu \mathrm{g} / \mathrm{mL}$ de hormônio folículo estimulante (FSH) associado ao hormônio luteinizante (Pluset®, Hertape Calier, Juatuba, MG) e cisteamina e/ou EGF de acordo com o grupo experimental. A incubação foi realizada em gotas $(100 \mu \mathrm{L})$ cobertas de óleo mineral durante $24 \mathrm{~h}$ a $38,5^{\circ} \mathrm{C}$ e $5 \%$ de $\mathrm{CO}_{2}$.

Para avaliação das células do cumulus após a MIV, os oócitos com estas células expandidas foram considerados maturados sob estereomicroscópio. Para a viabilidade celular, as células do cumulus foram removidas por pipetagens sucessivas em meio com $0,1 \%$ de hialuronidase por $2 \mathrm{~min}$. A suspensão celular resultante foi corada com azul de tripan $(0,2 \%) \mathrm{e}$ as células viáveis (não coradas) e não viáveis (coradas em azul) foram contadas nos quatro quadrantes externos utilizando câmara de Neubauer.

Para avaliação da maturação nuclear, os oócitos desnudos foram observados sob estereomicroscópio para verificação do primeiro corpúsculo polar que indicou a maturação. Em seguida, os oócitos foram fixados em paraformaldeído a 4\% em PBS por 30 min, lavados em PBS/BSA 0,4\% e marcados com Hoechst $33342(10 \mu \mathrm{g} / \mathrm{mL})$ por $15 \mathrm{~min}$. Os oócitos foram transferidos para lâminas de vidro e visualizados por microscopia de fluorescência onde somente oócitos apresentando núcleo na metáfase II (MII) e primeiro corpúsculo polar foram considerados maturados.

Além disso, os níveis de espécies reativas de oxigênio (EROs) foram quantificados utilizando o diacetato de 2',7'-diclorodihidrofluoresceína ( $\left.\mathrm{H}_{2} \mathrm{DCFDA}\right)$. Para tanto, os oócitos desnudados foram incubados com $5 \mu \mathrm{M}$ de $\mathrm{H}_{2}$ DCFDA por 30 min, colocados em lâminas de vidro e fotografados sob microscópio de fluorescência para quantificar a intensidade do sinal de fluorescência (pixels) utilizando o software ImageJ.

Para análise estatística, foram consideradas quatro repetições e os resultados foram expressos como média \pm erro padrão sendo analisados no StatView 5.0 (SAS Institute Inc., Cary, NC, EUA) considerando $\mathrm{P}<0,05$. A normalidade foi verificada com o teste de ShapiroWilk e a homocedasticidade foi verificada com o teste de Levene. Os níveis de EROs foram transformados em arco seno e analisados pela análise de variância (ANOVA), seguida do teste de Tukey. Todos demais dados foram comparados com um teste qui-quadrado.

\section{RESULTADOS E DISCUSSÃO}

Após quatro repetições, um total de 84 ovários bovinos foi obtido, resultando em 285 
oócitos viáveis, perfazendo uma média de 3,4 oócitos viáveis por ovário. Quanto à avaliação das células do cumulus (Tabela 1), inicialmente não foram observadas diferenças quanto às taxas de expansão dessas células, que variou de 68 a 73\% entre os tratamentos. Já em relação à viabilidade, os grupos CIS e EGF/CIS mostraram resultados superiores comparados ao grupo suplementado apenas com EGF $(\mathrm{P}<0,05)$. Esse resultado sugere que a presença de um antioxidante no meio (CIS) é essencial para manutenção da integridade celular, especialmente sabendo que as células do cumulus estão mais expostas aos processos de manipulação in vitro (DEUS et al., 2018). Dessa forma, estas células podem ser mais susceptíveis aos danos causados pelo estresse oxidativo na membrana plasmática e sua viabilidade contribui para a manutenção da qualidade oocitária (SANTOS et al., 2019). As células do cumulus atuam como proteção e como meio de comunicação do oócito com o meio de cultivo, permitindo a passagem de nutrientes e hormônios importantes para a adequada maturação (CALDER et al., 2003).

Tabela 1: Efeito da associação do EGF com cisteamina durante a MIV bovina.

\begin{tabular}{|c|c|c|c|c|}
\hline \multirow[t]{2}{*}{ Grupo } & \multicolumn{2}{|c|}{ Avaliação das células do cumulus } & \multicolumn{2}{|l|}{ Maturação nuclear } \\
\hline & Expansão, \% (n) & Viabilidade, \% $\left(n^{*}\right)$ & $1 \mathrm{~PB}, \%(n)$ & MII, \% (n) \\
\hline CIS & $68,0 \pm 11,0(51 / 75)^{a}$ & $68,6 \pm 3,2(1490 / 2172)^{\mathrm{a}}$ & $82,5 \pm 7,4(47 / 57)^{\mathrm{a}}$ & $83,3 \pm 4,1(20 / 24)^{\mathrm{a}}$ \\
\hline EGF & $70,0 \pm 10,8(56 / 80)^{\mathrm{a}}$ & $62,0 \pm 1,5(1536 / 2479)^{b}$ & $73,3 \pm 8,6(44 / 60)^{\mathrm{ab}}$ & $78,3 \pm 4,2(18 / 23)^{\mathrm{a}}$ \\
\hline EGF/CIS & $73,0 \pm 12,9(54 / 74)^{\mathrm{a}}$ & $66,4 \pm 2,3(1569 / 2364)^{\mathrm{a}}$ & $61,4 \pm 13,6(35 / 57)^{b}$ & $60,9 \pm 9,1(14 / 23)^{\mathrm{a}}$ \\
\hline
\end{tabular}

a,b: letras diferentes na mesma coluna indicam diferença entre os grupos $(\mathrm{P}<0,05) .{ }^{*}$ Células do cumulus.

A maturação nuclear é o principal indicativo de que o oócito está pronto para a fecundação. No presente trabalho, a presença do primeiro crepúsculo polar foi maior no grupo CIS em comparação ao EGF/CIS; enquanto o grupo suplementado apenas com EGF foi semelhante aos demais meios (Tabela 1). Essa avaliação da maturação, apesar de ser muito usada como método menos invasivo, ainda é considerada subjetiva especialmente devido à característica esférica do oócito. Por essa razão, é sempre interessante associar a avaliação subjetiva a avaliações mais específicas, como no presente trabalho que utilizamos a marcação fluorescente para avaliação mais precisa do estágio nuclear (Figura 1A). Nesse caso, não foi observada diferença entre os tratamentos quanto ao estágio nuclear de metáfase II (P > 0,05). Isso mostra que o EGF e a cisteamina podem não influenciar diretamente na maturação nuclear, mas sim na competência de desenvolvimento embrionário, sendo necessários mais estudos para esta avaliação.

Finalmente, com relação aos níveis de EROs (Figura 1E) também não houve diferença entre as suplementações adicionadas ao meio de maturação (Figura 1B, C, D). Sovernigo et al. (2017) também não observaram efeito da cisteamina sobre os níveis de EROs e maturação, 
porém o desenvolvimento embrionário foi melhor na presença desse antioxidante em comparação ao meio sem a presença do mesmo.

Figura 1: Oócitos bovinos avaliados quanto à maturação nuclear (A: oócito em metáfase II) e níveis de espécies reativas de oxigênio (B,C, D e E).

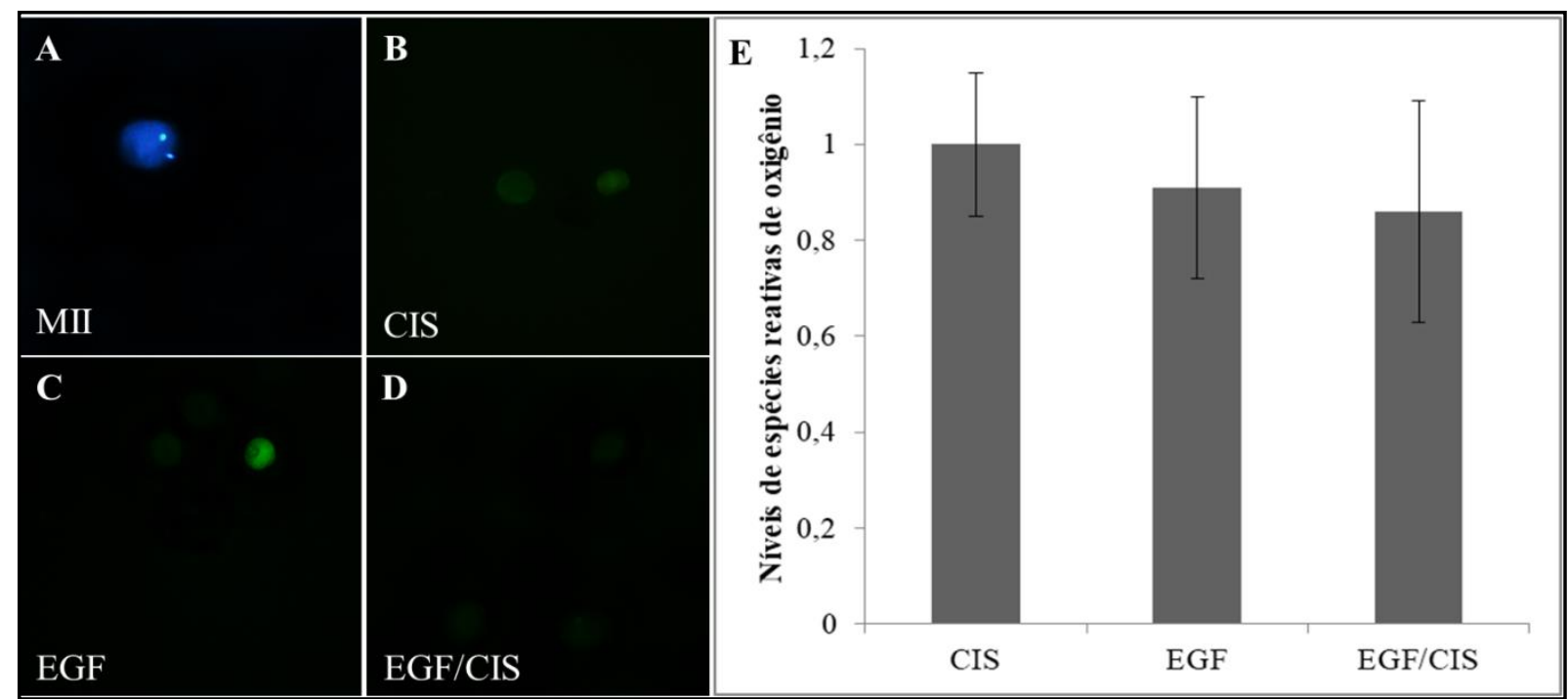

Fonte: Própria (2019).

\section{CONCLUSÕES}

A associação do EGF com a cisteamina não influencia a maturação oocitária de acordo com a avaliação do estágio nuclear. Contudo, a presença de cisteamina é essencial para a manutenção da viabilidade das células do cumulus e, consequentemente, da qualidade oocitária. Acredita-se que estudos avaliado o desenvolvimento embrionário desses oócitos após a MIV podem contribuir para uma melhor elucidação do papel do EGF associado à cisteamina.

\section{REFERÊNCIAS}

CALDER, M.D.; CAVENEY, A.N.; SMITH, L.C.; WATSON, A.J. Responsiveness of bovine cumulus oocyte-complexes (COC) to porcine and recombinant human FSH, and the effect of COC quality on gonadotropin receptor and $\mathrm{Cx} 43$ marker gene mRNAs during maturation in vitro. Reproductive Biology and Endocrinology, v. 1, p. 14-19, 2003.

DEUS, A.R.S.; SILVA, M.B.; SANTOS, M.V.O.; QUEIROZ NETA L.B.; BORGES, A.A.; PEREIRA, A.F. Influence of storage media during transport of bovine ovaries at $4^{\circ} \mathrm{C}$ on oocyte recovery and quality. ARS Veterinária, v. 33, p. 44-50, 2018.

DIELEMAN, S.J.; HENDRIKSEN, P.J.M.; VIUF, D.; THOMSEN, P.D.; HYTTEL, P.; KNIJN, H.M.; WRENZYCK, C.; KRUIP, T.A.M.; NIEMANN, H.; GADELLA, B.M.; BEVERS, M.M.; VOS, P.L.A.M. Effects of in vivo prematuration and in vivo final maturation on developmental capacity and quality of pre-implantation embryos. Theriogenology, v. 57, p. 5-20, 2002. 
OYAMADA, T; IWAYAMA, H; FUKUI, Y. Additional effect of epidermal growth factor during in vitro maturation for individual bovine oocytes using a chemically defined medium. Zygote, v. 12, p. 143-150, 2004.

RUMPF, R. Avanços metodológicos na produção in vitro de embriões. Revista Brasileira de Zootecnia, v. 36, p. 229-233, 2007.

SINGH, B.; MAL, G.; GAUTAM, S.K.; MUKESH, M. Reproduction biotechnology in cattle. Advances in Animal Biotechnology, p. 155-167, 2019.

SIRARD, M.A.; DESROSIER, S.; ASSIDI, M. In vivo and in vitro effects of FSH on oocyte maturation and developmental competence. Theriogenology, v. 68S, p. 71-76, 2007.

SOVERNIGO, T.C.; ADONA, P.R.; MONZANI, P.S.; GUEMRA, S.; BARROS, F.D.A.; LOPES, F.G.; LEAL, C.L.V. Effects of supplementation of medium with different antioxidants during in vitro maturation of bovine oocytes on subsequent embryo production. Reproduction in Domestic Animal, v. 52, p. 561-569, 2017.

WATSON, A.J.; SOUSA, P.; CAVENEY, A.; BARCROFT, L.C.; NATALE, D.; URQUHART, J.; WESTHUSIN, M.E. Impact of bovine oocyte maturation media on oocyte transcript levels, blastocyst development, cell number, and apoptosis. Biology of Reproduction, v. 62, p. 355-364, 2000. 